\title{
Direct evidence for coastal iodine particles from Laminaria macroalgae - linkage to emissions of molecular iodine
}

\author{
G. McFiggans ${ }^{1}$, H. Coe ${ }^{1}$, R. Burgess ${ }^{1}$, J. Allan ${ }^{1}$, M. Cubison ${ }^{1}$, M. R. Alfarra ${ }^{1}$, R. Saunders ${ }^{2}$, A. Saiz-Lopez ${ }^{2}$, \\ J. M. C. Plane ${ }^{2}$, D. J. Wevill ${ }^{3}$, L. J. Carpenter ${ }^{3}$, A. R. Rickard ${ }^{4}$, and P. S. Monks ${ }^{4}$ \\ ${ }^{1}$ Atmospheric Physics Group, Physics Dept., University of Manchester Institute of Science \& Technology, P.O. Box 88, \\ Manchester, M60 1QD, UK \\ ${ }^{2}$ School of Environmental Sciences, University of East Anglia, Norwich, NR4 7JT, UK \\ ${ }^{3}$ Chemistry Department, University of York, York, YO10 5DD, UK \\ ${ }^{4}$ Department of Chemistry, University of Leicester, Leicester, LE1 7RH, UK
}

Received: 10 December 2003 - Published in Atmos. Chem. Phys. Discuss.: 6 January 2004

Revised: 15 April 2004 - Accepted: 21 April 2004 - Published: 7 May 2004

\begin{abstract}
Renewal of ultrafine aerosols in the marine boundary layer may lead to repopulation of the marine distribution and ultimately determine the concentration of cloud condensation nuclei (CCN). Thus the formation of nanometre-scale particles can lead to enhanced scattering of incoming radiation and a net cooling of the atmosphere. The recent demonstration of the chamber formation of new particles from the photolytic production of condensable iodine-containing compounds from diiodomethane $\left(\mathrm{CH}_{2} \mathrm{I}_{2}\right)$, (O'Dowd et al., 2002; Kolb, 2002; Jimenez et al., 2003a; Burkholder and Ravishankara, 2003), provides an additional mechanism to the gas-to-particle conversion of sulphuric acid formed in the photo-oxidation of dimethylsulphide for marine aerosol repopulation. $\mathrm{CH}_{2} \mathrm{I}_{2}$ is emitted from seaweeds (Carpenter et al., 1999, 2000) and has been suggested as an initiator of particle formation. We demonstrate here for the first time that ultrafine iodine-containing particles are produced by intertidal macroalgae exposed to ambient levels of ozone. The particle composition is very similar both to those formed in the chamber photo-oxidation of diiodomethane and in the oxidation of molecular iodine by ozone. The particles formed in all three systems are similarly aspherical. When small, those formed in the molecular iodine system swell only moderately when exposed to increased humidity environments, and swell progressively less with increasing size; this behaviour occurs whether they are formed in dry or humid environments, in contrast to those in the $\mathrm{CH}_{2} \mathrm{I}_{2}$ system. Direct coastal boundary layer observations of molecular iodine, ultrafine particle production and iodocarbons are reported. Using a newly measured molecular iodine photolysis rate, it is shown that, if atomic iodine is involved in the observed particle bursts,
\end{abstract}

Correspondence to: G. McFiggans

(g.mcfiggans@umist.ac.uk) it is of the order of at least 1000 times more likely to result from molecular iodine photolysis than diiodomethane photolysis. A hypothesis for molecular iodine release from intertidal macroalgae is presented and the potential importance of macroalgal iodine particles in their contribution to $\mathrm{CCN}$ and global radiative forcing are discussed.

\section{Introduction}

Following extensive studies into coastal aerosol formation (O'Dowd et al., 1999, 2002) and recent insights into the production of iodine-containing particles from chamber studies of the photo-oxidation of diiodomethane (O'Dowd et al., 2002; Kolb, 2002; Jimenez et al., 2003a; Burkholder and Ravishankara, 2003), it has been proposed that the atmospheric oxidation of macroalgal iodocarbon emissions yield condensable iodine vapours and form the observed new particles. Incubation studies of kelps at Mace Head Atmospheric Research Laboratory $\left(53^{\circ} 19^{\prime} \mathrm{N}, 9^{\circ} 54^{\prime} \mathrm{W}\right)$, the site of many of the ultrafine particle measurement campaigns, have already shown that $\mathrm{CH}_{2} \mathrm{I}_{2}$ is the dominant organic iodine species released from the common rocky shore algae Laminaria digitata and Laminaria saccharina. $\mathrm{CH}_{2} \mathrm{I}_{2}$ readily photolyses to yield iodine atoms at ambient light levels. The subsequent reactions of iodine have been widely studied and used in investigations of marine boundary layer halogen cycling (McFiggans et al., 2000). The iodine monoxide radical (IO) is formed by reaction of iodine atoms with ozone and establishes a rapid steady state with iodine atoms owing to its rapid photolysis. Condensable iodine species are produced by the IO self-reaction and by the reaction of $\mathrm{IO}$ with the hydroperoxy radical $\left(\mathrm{HO}_{2}\right)$ or nitrogen dioxide $\left(\mathrm{NO}_{2}\right)$. The products 


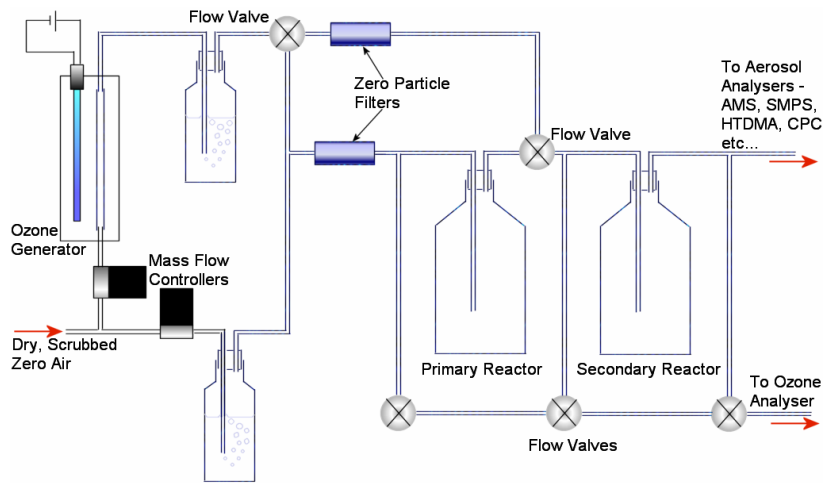

Fig. 1. Schematic of the laboratory apparatus. Dry, scrubbed air was bubbled through double deionised water and any particles were filtered out before passing through the primary reactor containing the Laminaria sample. Ozonised air was bubbled through double deionised water to remove free radicals and likewise scrubbed of particles prior to introduction either before or after the primary reactor. The reactors were kept in the dark or exposed to ambient light levels. All joints were glass or stainless steel. The exhaust from the primary reactor was passed into a secondary vessel to increase the reaction time before analysis of the particles formed.

of these reactions have been proposed to condense on preexisting supercritical embryos (so-called thermodynamically stable clusters, TSCs) leading to sufficiently rapid growth to significantly increase their lifetime with respect to coagulation. This stabilisation thereby increases their probability of growing to sizes where they can act as CCN. The TSCs are assumed to be supercritical in their nucleation mechanism, conceptually downstream of the saddle-point on their free energy surface and so more likely to grow in their nucleating vapours than evaporate. It has been postulated (Pirjola et al., 2000) that significant numbers of TSCs may exist in the clean marine boundary layer in the homogeneous nucleation of $\mathrm{H}_{2} \mathrm{SO}_{4}-\mathrm{H}_{2} \mathrm{O}-\mathrm{NH}_{3}$. However, it has been established that ambient ammonia and sulphuric acid were unable to explain condensational growth to observable sizes and that additional species were required (O'Dowd et al., 1999). Indirect in situ measurements have indicated that ultrafine particles are not sulphate dominated and may indeed contain iodine (Mäkelä et al., 2002). It has been hypothesised therefore that gaseous iodine compounds formed in the photo-oxidation of $\mathrm{CH}_{2} \mathrm{I}_{2}$ emitted from coastal macroalgae, condense onto ammonium sulphate clusters leading to an enhanced number of $\mathrm{CCN}$ in the marine boundary layer. However, it was discovered as long ago as 1928 (Dangeard, 1928; Kylin, 1929) that natural release of "free" iodine $\left(\mathrm{I}_{2}\right)$ from kelps, a process known as "iodovolatilisation", occurred leading to the higher iodine content of air in coastal areas (Dangeard, 1957). Consistent with this, very recent observations of molecular iodine $\left(\mathrm{I}_{2}\right)$ in the coastal boundary layer (Saiz-Lopez and Plane, 2004) at Mace Head indicate that $\mathrm{I}_{2}$, rather than iodocarbons, may be the dominant source of coastal reactive iodine. This study in- vestigates the formation of iodine-containing particles from kelps and discusses mechanisms for coastal $\mathrm{I}_{2}$ and particle production.

\section{Method and Results}

2.1 Laboratory investigation of particle production on exposure of Laminaria macroalgae to ozone

To investigate the coastal formation of new iodine-containing particles from intertidal macroalgae, we conducted a series of flow reactor experiments, exposing Laminaria digitata macroalgal samples cropped from intertidal rock pools to a flow of moderately ozonised air. Laminaria digitata specimens were cropped from the infralittoral zone at the Mace Head site. The specimens were placed in a $10 \mathrm{~L}$ reactor vessel and exposed to an ozonised stream of charcoal scrubbed, particle-free air under ambient light conditions and in the dark. The ambient light conditions were variable, but out of direct sunlight in a sea container on moderately bright lightly clouded days. The experiments were conducted over a period from 5 min to 2 days from cropping. The exhaust from the reactor was sampled using a TSI model 3081 scanning mobility particle sizer (SMPS), a TSI model 3025 condensation particle counter and an Aerodyne aerosol mass spectrometer (AMS) (Jayne et al., 2000; Allan et al., 2003). The SMPS was used in two ways; i) scanning the voltage on the central rod to measure the full distribution and ii) maintaining a series of constant voltages to deliver a range of monodisperse aerosol to the AMS. The AMS was used to measure full mass spectra of both the polydisperse distribution and the monodisperse size cuts and to build aerosol time-of-flight mass distributions of individual $\mathrm{m} / \mathrm{z}$ fragments (Jimenez et al., 2003b).

Two additional series of experiments were carried out. The first on samples of Laminaria hyperborea (Gunnerus) Foslie, also widespread around the Mace Head coastline, cropped from the Menai Straits between the North Wales mainland and the Island of Anglesey $\left(53^{\circ} 13^{\prime} \mathrm{N}, 4^{\circ} 11^{\prime} \mathrm{W}\right)$ and the second on samples of L. digitata (Huds.) Lamour (and also on L. saccharina (L.) Lamour) sampled near the Scottish Association for Marine Science laboratory at Dunstaffnage, near Oban, Scotland $\left(56^{\circ} 27^{\prime} \mathrm{N}, 5^{\circ} 26^{\prime} \mathrm{W}\right)$. The samples were cropped intact, transported in drums of seawater to UMIST and were kept at $3^{\circ} \mathrm{C}$ in cold room tanks exposed to a $16 \mathrm{~h}$ day $/ 8 \mathrm{~h}$ night light cycle. No attempt was made to replicate the solar light spectrum and the cold room lights used conventional tungsten filament lamps. The seawater was frequently replenished with filtered seawater from the location where they were cropped. The samples ranged from 15 to $20 \mathrm{~cm}$ for Dunstaffnage Laminaria saccharina samples up to $1.5 \mathrm{~m}$ for Menai Strait Laminaria hyperborea. Experiments were conducted on both whole macroalgal plants and cut strips of frond. The particle production rate was not 
Table 1. Truth table showing the system response to ozone introduction position and light conditions. The ozone mixing ratios are representative values for the experiments measured when particle production has essentially ceased. In many cases particle production was observed at very much lower mixing ratios (a few tens of ppb), though this was not always repeatable, being dependent on the number of previous exposures, light levels etc. The light levels were not controlled in these experiments and depended solely on the ambient insolation. $1^{\circ}$ and $2^{\circ}$ represent primary and secondary vessels respectively.

\begin{tabular}{ccccccc}
\hline & \multicolumn{3}{c}{$1^{\circ}$} & \multicolumn{2}{c}{$2^{\circ}$} & Particles \\
\hline 1 & Seaweed & $\mathrm{O}_{3}$ in/ppb & $\mathrm{h} v$ & $\mathrm{O}_{3}$ in/ppb & $\mathrm{h} v$ & \\
\hline 2 & $\sqrt{ }$ & Yes/100 & $\sqrt{ }$ & No & No & $\sqrt{ }$ \\
3 & $\sqrt{ }$ & Yes/100 & $\sqrt{ }$ & No & $\sqrt{ }$ & $\sqrt{ }$ \\
4 & $\sqrt{ }$ & No & $\sqrt{ }$ & Yes/200 & $\sqrt{ }$ & $\sqrt{ }$ \\
5 & $\sqrt{ }$ & No & $\sqrt{ }$ & Yes/100 & No & No \\
6 & $\sqrt{ }$ & Yes/100 & No & No & $\sqrt{ }$ & $\sqrt{ }$ \\
7 & $\sqrt{ }$ & No & No & Yes/100 & $\sqrt{ }$ & $\sqrt{ }$ \\
8 & $\sqrt{ }$ & No & $\sqrt{ }$ & No & $\sqrt{ }$ & No \\
9 & $\sqrt{ }$ & Yes/>500 & No & No & No & No \\
10 & Seawater only & Yes/>500 & $\sqrt{ }$ & No & No & No \\
\hline
\end{tabular}

noticeably affected, only the time for which the particle production continued at a given ozone concentration; normally whole plants were used, allowing for longer experiments. The algal tissue was neither damaged during the cropping process nor showed visible sign of damage throughout the experiments. Only under extreme experiments with many hours of exposure to high ozone concentrations, repeated over several days, was there discolouration and dryness.

These latter two series of experiments allowed variation in the geometry of the experimental setup ensuring elimination of potential artefacts in the original experiments, but otherwise provided data entirely consistent with the experiments conducted in situ at Mace Head. Figure 1 shows a schematic of the experimental apparatus. An ozone analyser (Monitor Labs ML8810) and a more directly adjustable ozone generator (PenRay model SOG-2) were used to more accurately control and measure the ozone concentration. Together, these experiments provide the first direct evidence for ultrafine particle production from coastal macroalgae under atmospheric and close to atmospheric conditions. Total flow rates in the experiments were largely determined by the required flow rates for the sampling instrumentation but ranged from 0.4 to $2.5 \mathrm{~L} \mathrm{~min}^{-1}$. The flows in the zero air and ozonised air lines were independently controlled, but in all cases pre-scrubbed through charcoal and filtered for particles. Both flows were bubbled through water; the ozone line to scrub hydroxyl radicals and the air line to maintain a humid flow to ensure that the Laminaria did not dry out. A range of ozone mixing ratios from zero to around 300 parts per billion (ppbv) was used for the experiments.

Table 1 is a "truth table" summarising the system response to experimental conditions. It can be seen that no particles were formed in the absence of either light or ozone. It was initially found that no particles were formed unless ozonised air passed directly over the sample - i.e. post-mixing of even elevated ozone concentrations with ozone-free air that has passed over the seaweed will not lead to particle formation within the residence time between the post flow reactor ozone inlet and the sampling instruments. However, addition of a secondary reaction vessel, which increased the post-exposure residence time, led to significant particle detection whether the ozonised air was introduced prior to, or after, the primary reactor. This suggests that any particles formed from precursors released by the seaweed do not have time to grow to a size which can be detected by the particle counter when the ozone was introduced after the seaweed reactor under the original experimental configuration - i.e. they remain significantly smaller than $3 \mathrm{~nm}$ in the shorter residence time corresponding to the tubing between the primary reactor and particle detectors. However, the increased (several minutes) residence time corresponding to the secondary reactor is comparable to or greater than the transit time across the intertidal zone at Mace Head. It is proposed that in both the laboratory experiment and the open coastal atmosphere, the transit time plays an important role in the growth of particles to a size detectable by instrumentation. Indeed, in general it was found that, as the characteristic residence time in the system decreased (by increasing the gas flow rate), the threshold ozone concentration required to form detectable particles increased. This is expected, since the smaller the residence time the greater required rate of condensable vapour production to form particles of detectable size.

Importantly, it must be recognised that these experiments involve living biological systems and the factors controlling the Laminaria iodine metabolism are not entirely understood. Active control of these factors was therefore not attempted other than to ensure measurable experimental conditions including flow rates, gas concentrations, humidity and either 


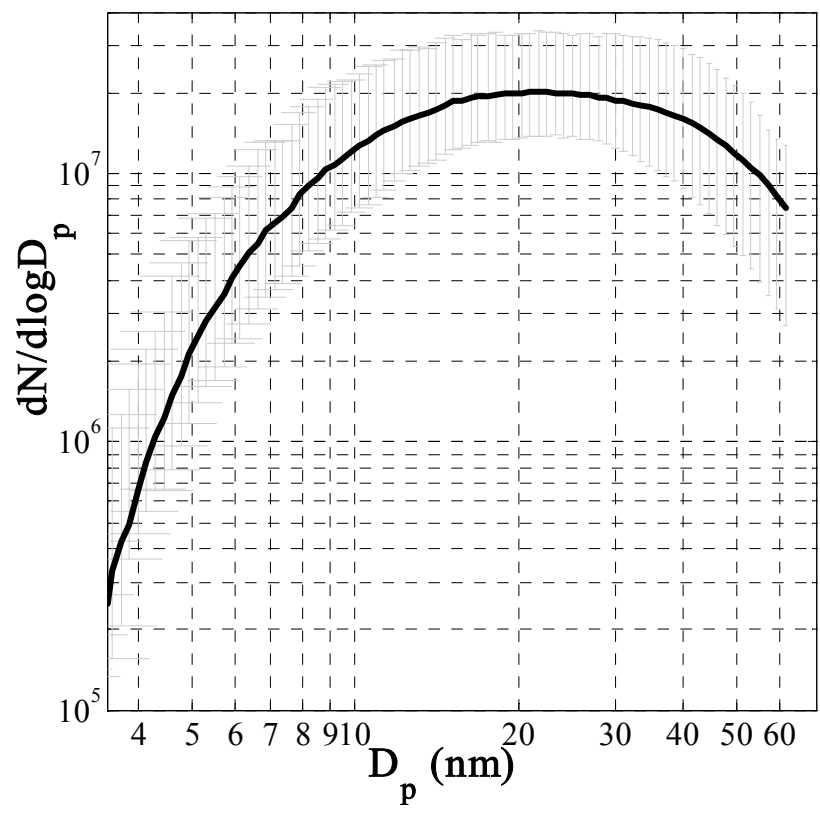

Fig. 2. The average of seven aerosol mobility size distributions measured by the SMPS over several days with four Laminaria samples exposed to the same elevated ozone level (around $300 \mathrm{ppb}$ ) and illuminated by ambient daylight at Mace Head. The bars show the maximum and minimum concentrations at each size. It can be seen that the distributions are extremely repeatable under these conditions.

light or dark. The light level was that provided by a partially glazed laboratory roof and thus was not controlled over a period of several months. The results presented simply contrast the system behaviour when exposed to daylight and when blacked out by a darkroom curtain - no control of light level was used in these experiments due to the configuration. Additional contributions to the variability may have been due to the increasing age of the specimens since being cropped throughout the experimental programme. The experiments were carried out over several months on different samples cropped at the same time, however no qualitative and little quantitative difference in the particle forming ability was found using the same conditions at the beginning and end of the programme. The resulting behaviour in terms of, for example, absolute particle concentrations formed or representative ozone concentrations for particle detection varied between experiments but followed the trends described above and presented in Table 1.

It was noted that multiple additions of the same ozone concentration to either the primary or secondary reactor to the same individual plants produced continually reducing numbers of particles. It was also noted that the plants "recovered" with time, such that re-exposure to the original ozone concentration led to increased numbers again. The absolute magnitude of the decline and the time required to recover were again variable and depended on the exposure time, the number of exposures and varied between plants. The results presented are those from fresh or fully recovered specimens, meaning that the particle properties illustrated in Table 1 (and Figs. 2 to 5) are those produced during the initial exposure stage of the experiment. In the experiments where ozone was directly flowed into the primary reactor, the steady-state mixing ratio of ozone for a given lamp exposure and flow rate in an empty primary reactor was initially significantly lower on addition of a Laminaria specimen; for example, only a few ppb measured at outlet compared with $200 \mathrm{ppb}$ for an empty reactor. The mixing ratio in the reactor reached this temporary steady state after some $10 \mathrm{~min}$ depending on flow rate, as did the measured particle size distribution. The particle production diminished after several tens of minutes exposure to such high ozone levels. Elevated ozone levels have been used experimentally to trigger cell death (Rao et al., 2000). The reduction and eventual cessation of particle production would be entirely consistent with the triggering of cell death apart from the fact that at least partial (and often full) recovery of the particle production was observed after switching off the ozone lamp for several hours. For example, switching off the lamp after an afternoon experiment and re-exposing the specimen to ozone the next morning led to particle production on the same scale as the initial exposure the previous afternoon. The recovery was repeatable from specimen to specimen. Often, high ozone exposure for even $12 \mathrm{~h}$ would not prevent recovery. Surprisingly, particle formation was observed on exposure of rehydrated dead dried Laminaria japonica specimens to ozone, though no recovery was evident after suspended exposure. This demonstrates that recovery, though not precursor release, requires live macroalgae. The ozone levels reported are those after the reactor once particle production has ceased entirely, hence representing the "potential" ozone concentration throughout the experiment that which would be present in the absence of macroalgae or particle production chemistry. Most importantly, as already stated, it was not necessary to expose the specimen to ozone to initiate particle formation. Similar levels of particle production were observed flowing the ozone into the secondary reactor, the Laminaria only exposed to zero air. The comparable response indicates that the particle precursor is not only released as a result of ozone exposure but that ozone is required in the particle formation mechanism itself. In a similar fashion, the ozone levels reported in these experiments is the ozone concentration after particle production has ceased. A mass budget analysis between ozone consumed and particles formed is being incorporated into an ongoing investigation into the details of the particle production and growth mechanism.

Size distribution measurements showed that the numbers and sizes of particles formed were extremely repeatable with the total aerosol number and volume increasing with increased ozone concentration. Figure 2 shows the average of 7 distributions taken with different specimens over three days during the Mace Head measurements at the same elevated 


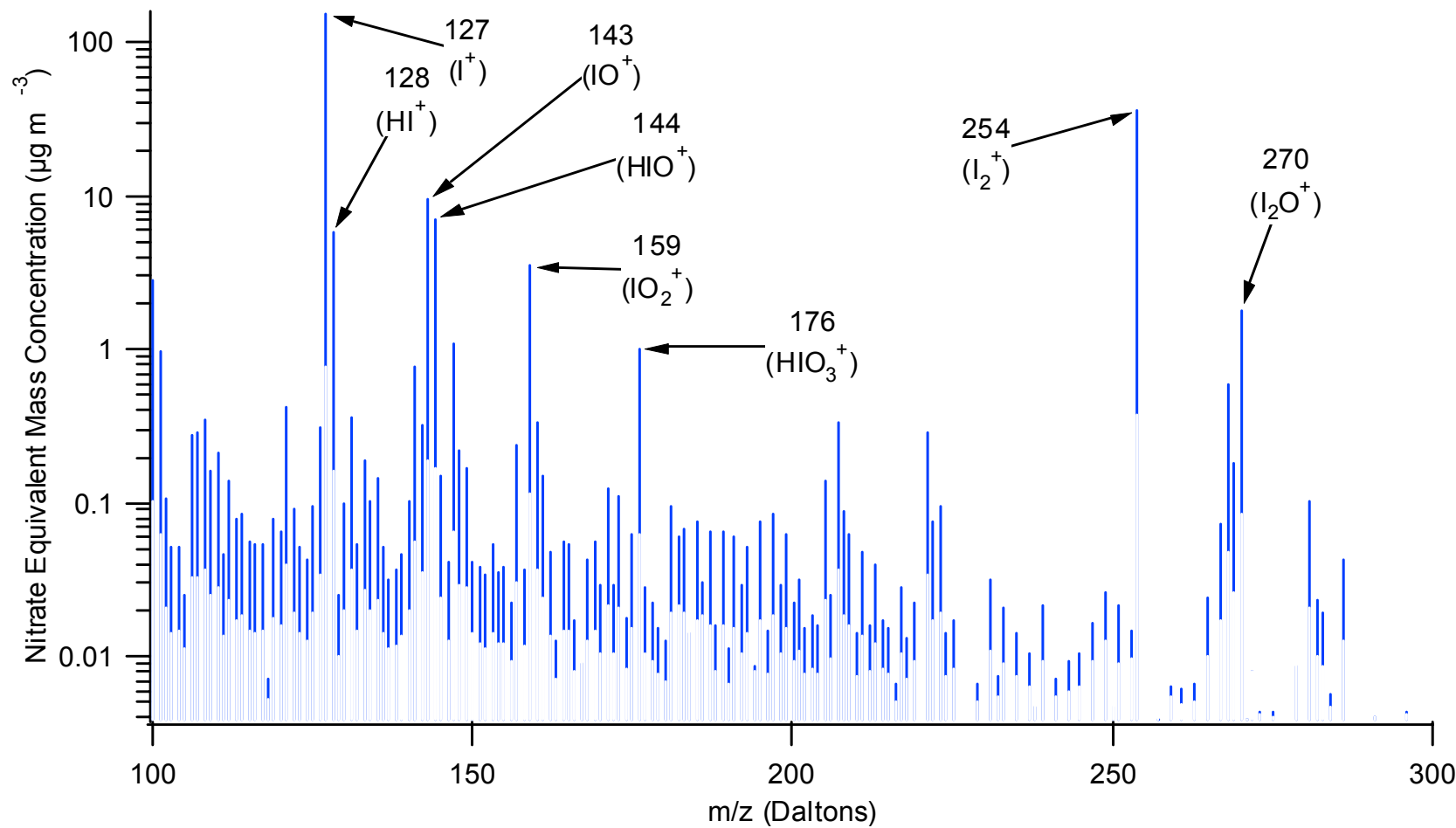

Fig. 3. A typical positive ion mass spectrum taken with the AMS of particles formed from the exposure of Laminaria digitata to $500 \mathrm{ppb}$ of ozone at Mace Head. The major iodine fragments are identified. All the major mass fragments are consistent with being derived from iodine oxides or iodine-containing oxyacids.

ozone concentration (of the order of $300 \mathrm{ppbv}$ ); the error bars indicate the extent of the macroalgal specimen-to-specimen variability.

Increasing the ozone concentration further (to around $500 \mathrm{ppbv}$ ) with the increased residence time, it was possible to grow the aerosol to sizes significantly greater than the lower size cut-off of the AMS, limited by the configuration of the aerodynamic lens inlet. Zhang et al. (2002) have used computational fluid dynamic calculations to describe the transmission through a single orifice and have expanded this to model the aerodynamic lens system used in this study showing that it has a lower size cut off of $30 \mathrm{~nm}$. Figure 3 shows a typical mass spectrum of particles formed in the exposure of L. digitata to ozone. It can be seen that all the major mass fragments are consistent with being derived from iodine oxides or iodine-containing oxyacids, as they were in the chamber study of the photolysis of $\mathrm{CH}_{2} \mathrm{I}_{2}$ (O'Dowd et al., 2002; Jimenez et al., 2003a) and that the same fragments are present $\left(\mathrm{I}^{+}, \mathrm{HI}^{+}, \mathrm{IO}^{+}, \mathrm{HIO}^{+}, \mathrm{IO}_{2}^{+}, \mathrm{HIO}_{3}^{+}, \mathrm{I}_{2}^{+}\right.$and $\left.\mathrm{I}_{2} \mathrm{O}^{+}\right)$. Although the plot in the figure does not show fragments below $m / z 100$, the $m / z$ fragments corresponding to sulphate ( $\mathrm{SO}^{+}, \mathrm{SO}_{2}^{+}, \mathrm{SO}_{3}^{+}, \mathrm{HSO}_{3}^{+}$and $\mathrm{H}_{2} \mathrm{SO}_{4}^{+}$at $48,64,80,81$ and 98 respectively) and nitrate $\left(\mathrm{NO}^{+}\right.$and $\mathrm{NO}_{2}^{+}$at 30 and 46$)$ were absent indicating that there was little mass contribution in the aerosol from either species. Although this cannot en- tirely eliminate the participation of sulphur or nitrogen containing species in the particle formation process, the scrubbing and filtration of the flowstream should have minimised the influx of condensable material into the system.

By positioning the SMPS upstream of the inlet, it was possible to introduce monodisperse size cuts into the AMS. Building mass distributions of selected iodine mass fragments as a function of vacuum (more correctly "free molecular") aerodynamic diameter, it was then possible to estimate the effective density of the particles by equating the modal aerodynamic diameter to the mobility diameter of the monodisperse cut. Figure 4a shows the mass distribution of the $\mathrm{I}^{+}$and $\mathrm{I}_{2}^{+}$fragments $(\mathrm{m} / z$ fragments 127 and 254) in $120 \mathrm{~nm}$ mobility diameter particles. Figure $4 \mathrm{~b}$ shows plots of the aerodynamic mode diameter of these fragments for a range of mobility diameters. The slope of the plots shows that the effective density, a measure of the material density and the shape of the particles is of the order of $3.5 \mathrm{~g} \mathrm{~cm}^{-3}$. This is lower than the density of higher oxides of iodine such as $\mathrm{I}_{2} \mathrm{O}_{5}\left(4.78 \mathrm{~g} \mathrm{~cm}^{-3}\right)$, indicating particle asphericity if they are made of such materials. For details of this analysis, the reader is referred to Jimenez et al. (2003a). 

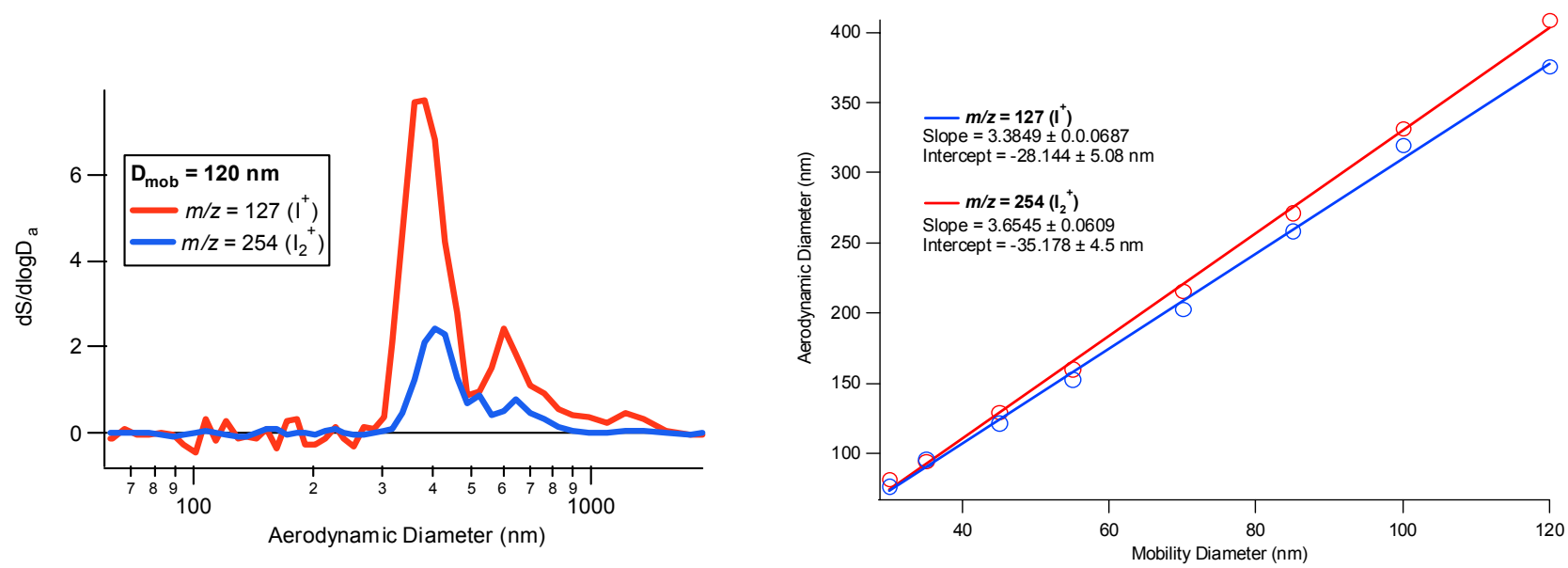

Fig. 4. (a) The aerodynamic size distribution of mass fragments at $m / z=127$ and 128 corresponding to $\mathrm{I}^{+}$and $\mathrm{I}_{2}^{+}$for a mobility size cut at $120 \mathrm{~nm}$. Derived from a range of these mass distributions selected at different mobilities, (b) shows the aerodynamic mode diameter plotted against the mobility diameter. The slope of the plot gives the effective density. See text and Jimenez et al. (2003a).

2.2 Particle formation in the reaction of molecular iodine with ozone

A sequence of experiments was conducted to investigate the formation of particles in the light and dark reactions of molecular iodine with ozone. The experimental apparatus was slightly modified to pass air across the headspace of a small trap containing crystalline iodine at a known temperature, thus controlling the molecular iodine vapour pressure. Again, particles formed mixing this airstream with ozonised air were sampled with a variety of instrumentation, and again extremely high and repeatable particle number concentrations were observed throughout a range of ozone and iodine concentrations. The particle composition was found to be very similar in these and the seaweed exposure experiments to those formed in the chamber photo-oxidation of $\mathrm{CH}_{2} \mathrm{I}_{2}$; consistent with the particles comprising almost exclusively iodine oxides and oxy-acids. Figure 5 shows the mass spectra from each of the three systems - it is evident from the relative fragment intensity that the particles formed in all systems have extremely similar composition. In the exposure of molecular iodine to ozone, particles were formed both in the presence and absence of light, contrary to atmospheric observations, the seaweed experiments and the findings of the chamber study. However, particle formation in the dark was less intense than at ambient light levels, requiring extremely high ozone and iodine mixing ratios; much higher than may be expected in the atmosphere (of the order of ppm - for a discussion of the vapour pressure of molecular iodine and the control of iodine concentration used in this experiment, see Saiz-Lopez et al., 2004). Reducing the iodine and ozone concentration towards ambient levels, particle production in the dark became undetectable. Vikis and MacFarlane (1985), Sunder et al. (1985) and Sunder and Vikis (1987) made studies of the reaction rate and products in the $\mathrm{I}_{2}+$ $\mathrm{O}_{3}$ reaction under light and dark conditions. The products were not tracked in the current study, but the concentration of reactants are comparable to those used in the Vikis and MacFarlane (1985) study $\left(\mathrm{I}_{2}\right.$ from 1 to $10 \times 10^{14}$ and $\mathrm{O}_{3}$ of 1 to $100 \times 10^{14}$ molec. $\mathrm{cm}^{-3}$ respectively compared with 6 to $30 \times 10^{14}$ and 3 to $12 \times 10^{15}$ ). These concentrations are substantially higher than those measured in the atmosphere (see Sect. 3 below), but are used to produce high concentrations of particles of sizes suitable for analysis with the instrumentation detailed below. In addition, the atmospheric measurements are integrated long-path observations and therefore it is expected that local molecular iodine concentrations will be much higher.

The seaweed experiments were all conducted under humid conditions with moist Laminaria specimens. The molecular iodine experiments were conducted under both dry and moist conditions. In all experiments, the particles were significantly more compact and dense than those formed in the $\mathrm{CH}_{2} \mathrm{I}_{2}$ chamber photo-oxidation. Those formed under dry conditions in the chamber study possessed distinct fractal morphology. This was not so evident for the particles formed in the current study. Particles were captured on holey carbon film coated copper mesh grids (Agar Scientific). Transmission Electron Microscope (TEM) imaging and analysis was carried out using a JOEL 2000EX instrument, operating at $200 \mathrm{kV}$, with associated X-ray microanalyser. The X-ray analysis will not be presented here, as this is the subject of further studies. Figure 6 shows a TEM image of a particle formed in the light reaction of molecular iodine and ozone; those formed in the seaweed experiments are equally compact. It appears that the particles formed in the reaction of molecular iodine with ozone do not clearly exhibit the degree of fractal morphology inferred from the $\mathrm{CH}_{2} \mathrm{I}_{2}$ chamber 

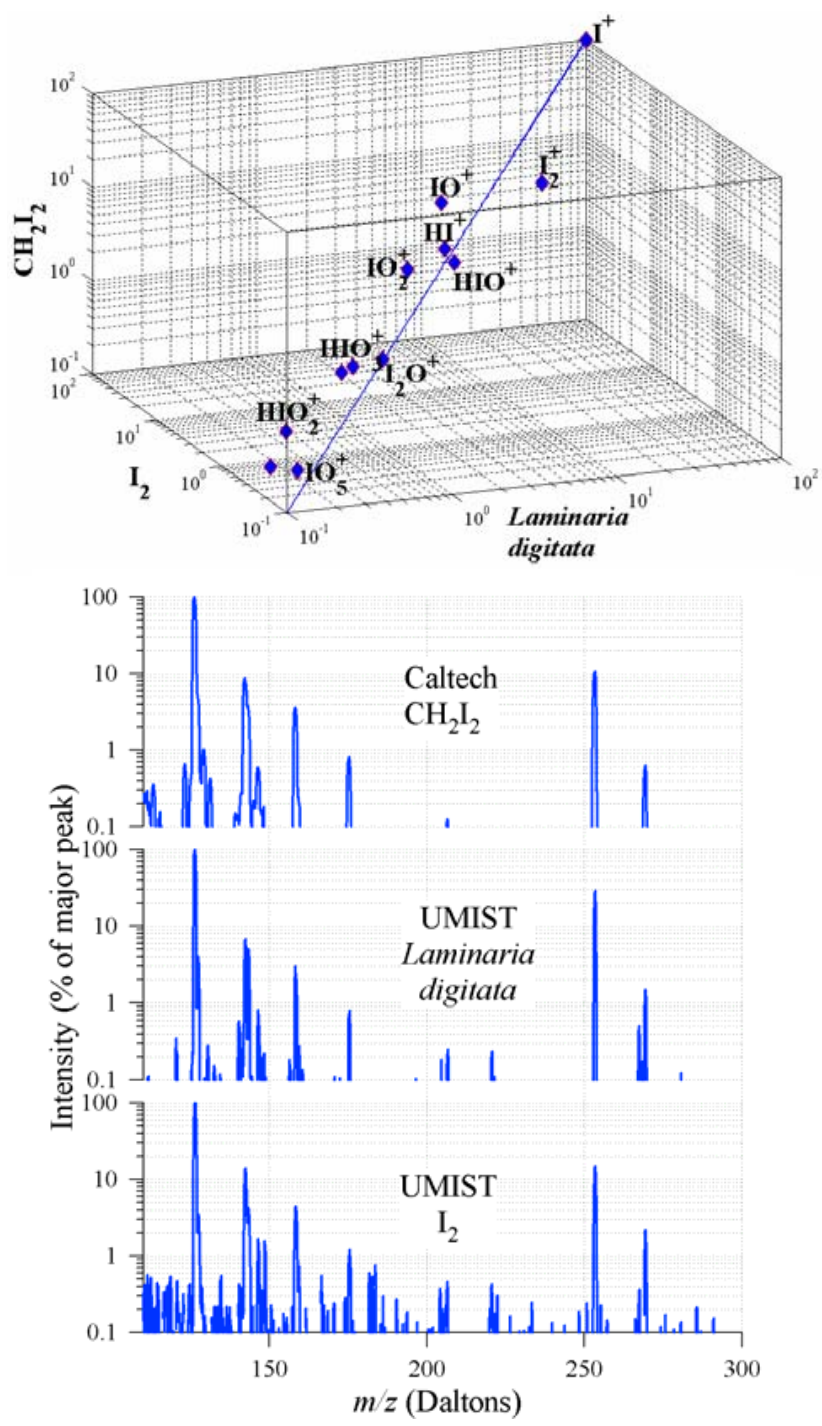

Fig. 5. Mass spectra from each of the three systems i) $\mathrm{CH}_{2} \mathrm{I}_{2}$ exposed to ozone in the study reported in O'Dowd et al. (2002) and Jimenez et al. (2003a), ii) Laminaria digitata and iii) iodine vapour exposed to ozone, this study. It can be seen that the mass spectra of the particles formed in each system are extremely similar. A scatter plot of the major mass fragments in each system is shown in the top panel. It may be inferred that the particles have the same composition in each case.

experiments, possessing a more compact agglomorate form consistent with the effective density of those formed passing ozone over Laminaria macroalgae. This may be more due to the differences between the formation conditions in the flow and chamber experimental configuration than in the chemistry and it is not possible to positively identify the participating species from these particle morphology differences.

In order to investigate the behaviour of the particles when exposed to water vapour, a hygroscopicity tandem differential mobility analyser (HTDMA) was used (Rader and

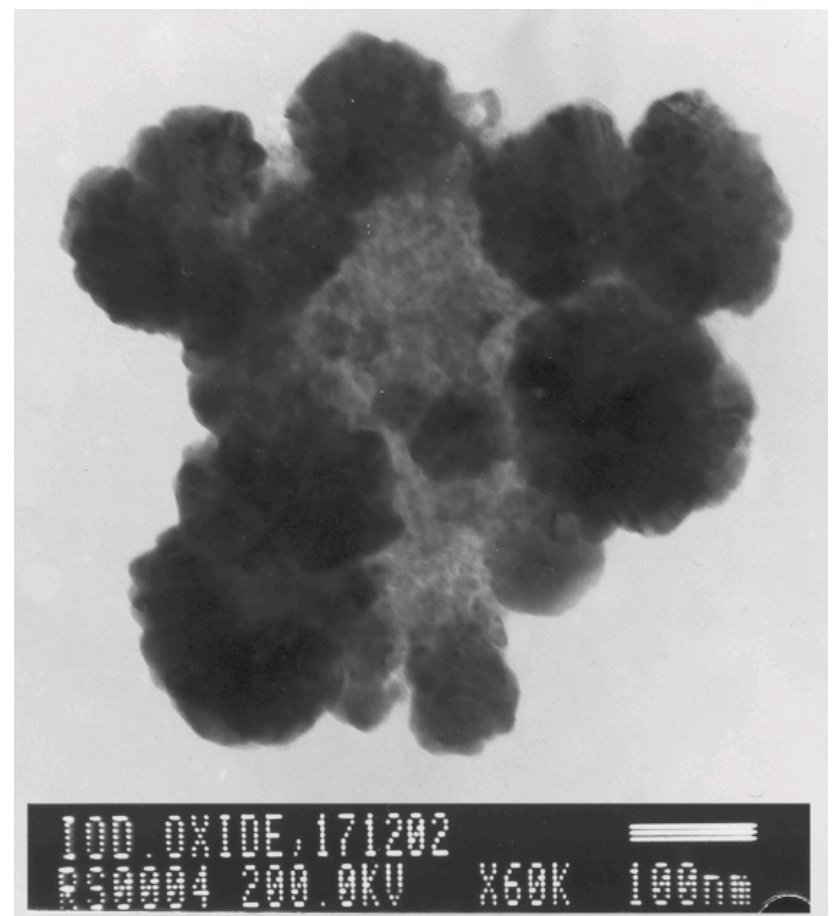

Fig. 6. TEM image of a particle formed in the light reaction of molecular iodine and ozone.

McMurry, 1986). This instrument relies on measuring the change in size of a particle by monitoring the change in its electrical mobility after increasing the humidity of its environment. In the HTDMA, a Vienna-type differential mobility analyser (DMA) (Winklmayr et al., 1991) selects a nearmonodisperse distribution of dry particles $(<10 \% \mathrm{RH})$ from the polydisperse distribution sampled from the reactor output. The monodisperse size cut of particles is then exposed to a controlled humidity environment before being passed into the second DMA. Rapid and accurate humidity control is achieved through mixing of dry and saturated airflows using computer controlled variable flow pumps. Particles taking up water normally exhibit growth in the humid environment. The second DMA is scanned over an appropriate size range and the size-selected particles are counted using a condensation particle counter (CPC) (TSI model 3760). A plot of size from the second DMA versus CPC particle count will then give a distribution determined by the change in size of the original monodisperse population and a broadening effect due to the instrument transfer function. In order to remove this broadening effect of the two DMAs, a modified optimal estimation method (OEM) after Rodgers (2000) was used, ensuring that the reported distribution reflected only the particles' change in size (this procedure is the subject of a detailed Technical Note; Cubison et al., personal communication, 2004). Figure 7 shows dry to $90 \%$ RH growth factor $\left(\mathrm{GF}_{D}\right)$ distributions measuring the particles produced in both 

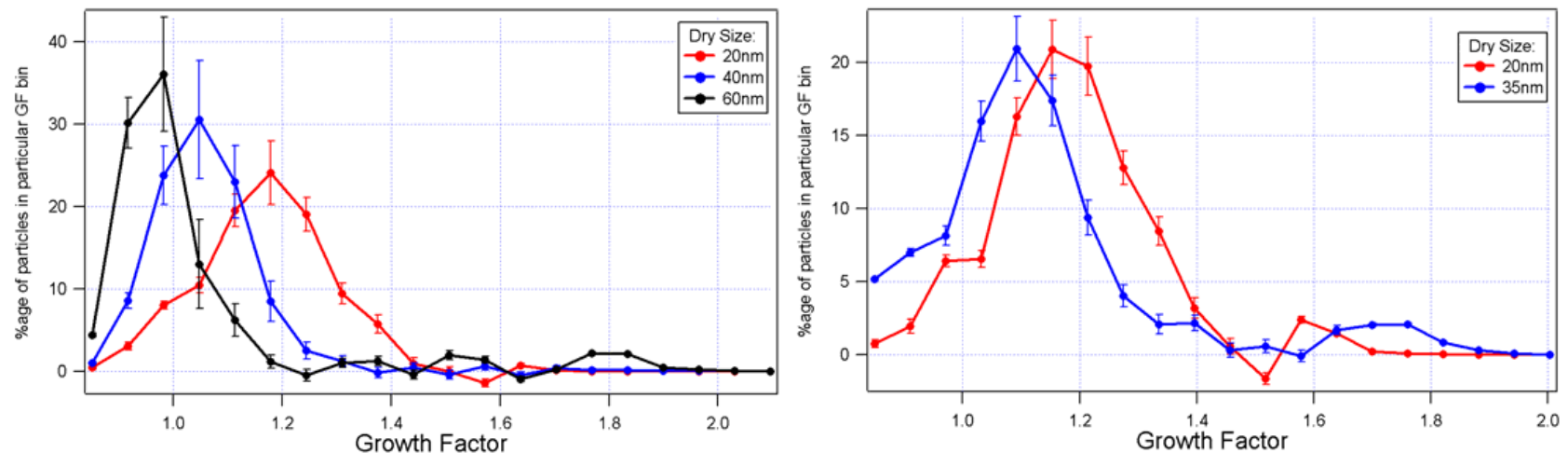

Fig. 7. Growth factor of particle formed in the light (left panel) and dark (right panel) reactions of molecular iodine and ozone. The growth factor is the ratio of the mobility sizes measured at $90 \%$ relative humidity and at $<10 \%$. It can be seen that those particles that have grown to larger dry sizes in both experiments exhibit lower growth factors. In the light experiment, where particles of $60 \mathrm{~nm}$ diameter were formed in sufficient numbers to be sampled, a significant proportion of these particles were shown to shrink on exposure to high humidity. This is consistent with those formed on exposure of $\mathrm{CH}_{2} \mathrm{I}_{2}$ to ozone. One possible explanation is the collapse of aspherical particles due to capillarity effects as exhibited by soot agglomerates.

the light and dark reactions of $\mathrm{I}_{2}$ with $\mathrm{O}_{3}$. It can be seen that very similar trends apply. Rather than growing due to an increase in the bound water content of soluble material in the particles with increasing humidity, the particles appear to be less hygroscopic the larger the dry size. This trend is consistent across all sizes in the dark reaction (almost no particles were formed larger than $35 \mathrm{~nm}$ diameter in the dark reaction, even with extremely elevated $\mathrm{I}_{2}$ and $\mathrm{O}_{3}$ levels). In the light reaction, growth factor distributions were statistically indistinguishable at the lower sizes from those of the particles formed in the dark reaction. At larger sizes (mobility diameter $60 \mathrm{~nm}$ ), beyond the largest formed in the dark reaction, the particles actually shrank significantly in the more humid environment. The implication is that the particles collapse more completely due to capillarity forces when they are larger, indicating that they become less compact with increasing size. This reflects the mode of growth of the particles. In contrast to the findings from the chamber studies of Jimenez et al. (2003), this trend was the same whether the particles were initially formed in a dry or a humid environment. However, it is not known whether the hygroscopic behaviour of particles formed in the $\mathrm{I}_{2}$ experiment in a flow reactor or in the $\mathrm{CH}_{2} \mathrm{I}_{2}$ chamber experiments was closer to that of those formed by Laminaria in coastal airmasses. Vakeva et al. (2002) reported measurements made during Mace Head particle bursts. It is not straightforward to make comparisons between results from the field measurements and the laboratory studies. The field measurements were made with a socalled UF-TDMA on smaller particles than those examined in the laboratory. In any case, the nucleation mode particles were of low growth factor during particle bursts. In our study and that of Jimenez et al. (2002), the growth factors were also found to be low and to decrease with increasing size, collapsing more readily on absorption of water. The 8 and
$10 \mathrm{~nm}$ particles in the Vakeva et al. (2002) study were found to swell less than our $20 \mathrm{~nm}$ particles. This appears contrary to the trend in the current study, but it would be expected that, as the Kelvin term becomes appreciable (below 10 to $15 \mathrm{~nm}$ ) the growth factor will be suppressed with decreasing size. A maximum in growth factor will occur at a dry size above that where the Kelvin term dominates, but below that where the particles become significantly less compact.

In all experiments, particle-free scrubbed air was used in both the air and ozone lines. Gaseous $\mathrm{H}_{2} \mathrm{SO}_{4}$ was expected to be below the threshold required for nucleation. It can be concluded that iodine species alone are responsible for both the nucleation and condensational growth of particles in the experiments. This is borne out by the absence of any significant mass of non-iodine fragments in the mass spectra of particles grown up to detectable sizes (with higher than ambient ozone concentrations). Certainly, in the seaweed system, no mass spectrometric signal characteristic of any sulphate fragment was detected above the instrumental noise indicating that there is no significant amount of sulphate mass. Whilst it cannot be categorically stated that there is no sulphate nucleus upon which the iodine species condense, it may be considered unlikely. Since large numbers of particles are formed at ambient ozone concentrations (too small to have their composition probed but large enough to be detected and sized), there is no reason to suspect that a thermodynamically stable sulphate cluster is required for nucleation to occur. It only remains to ascertain whether the condensation of iodine containing vapours on such clusters competes with homogeneous iodine oxide nucleation in the open atmosphere. 


\section{Daytime observations of molecular iodine in the ma- rine boundary layer}

As discussed above and as shown in Fig. 5, it is not possible to unambiguously attribute the formation of new particles to a particular precursor solely based on discrepancies between the properties of particles formed in the laboratory ozonolysis experiments. Suspecting that there was a possible inorganic source of iodine atoms playing a role both in cycling of reactive halogens and in the production of particles, it was decided to search for a variety of iodinecontaining species using differential optical absorption spectroscopy (DOAS). During the North Atlantic Marine Boundary Layer Experiment (NAMBLEX) at Mace Head the longpath DOAS instrument was used to measure ambient concentrations of gaseous molecular iodine. The instrument consists of a Newtonian telescope and a $0.5 \mathrm{~m}$ Czerny-Turner spectrometer coupled to a two-dimensional charge coupled detector. The transmitting Newtonian telescope was located in a cottage on the shoreline at Mace Head and the light beam was folded back to the transmitter by a retro-reflector situated $4.2 \mathrm{~km}$ away on Croaghnakeela Island, providing an effective optical path of $8.4 \mathrm{~km}$ over the sea surface. The spectral region between $535-575 \mathrm{~nm}$ was utilised for spectral analysis of $\mathrm{I}_{2}$ with a resolution of $0.25 \mathrm{~nm}$. In addition to recording atmospheric spectra (i.e. the light beam from the retro-reflector array plus scattered sunlight), spectra of the scattered sunlight and the xenon lamp were also taken. This enabled a process spectrum to be derived, which is the atmospheric spectrum minus the scattered light spectrum. This spectrum was then converted into differential absorption spectra by using a Fast Fourier Transform (FFT) routine (Allan et al., 2001) Spectra were recorded for $30 \mathrm{~min}$ for each $\mathrm{I}_{2}$ measurement. The concentrations were then derived using a least squares singular value decomposition routine comparing the atmospheric spectra with a set of reference spectra. The molecular iodine reference spectrum was obtained from the corresponding cross-section measured in the laboratory (Saiz-Lopez et al., 2004) adapted to the instrument function of the DOAS spectrometer.

Owing to the extensive range of species being investigated across a broad range of wavelengths with different diurnal patterns, the $\mathrm{I}_{2}$ absorption region was not continuously monitored. Instead, the regions of interest were stepped through sequentially. An extensive dataset of molecular iodine spectra were taken over a period of a month (Saiz-Lopez and Plane, 2004). However, most of these were at night. Since particle bursts are almost exclusively observed during the daytime, the most relevant measurements are obtained from the daytime spectra. Figure 8 shows the measurements from each of the three daytimes when spectra were recorded in the $I_{2}$ wavelength region. It can be seen that on two of the days, 25 and 26 August 2002, the levels of $I_{2}$ were frequently above the detection limit, reaching peak mixing ratios in excess of 25 parts per trillion (ppt).

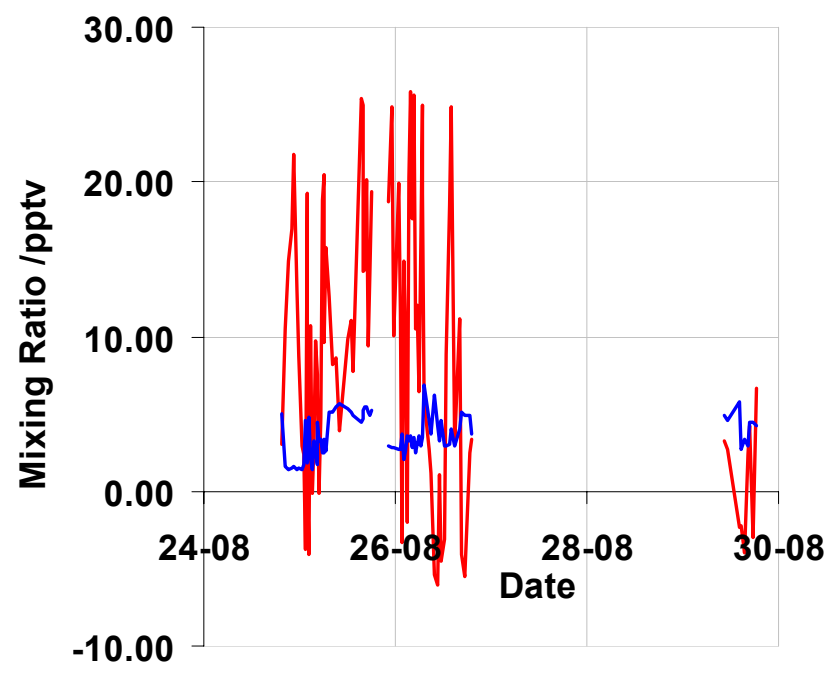

Fig. 8. DOAS measurements of $I_{2}$ from each of the three daytimes when spectra were recorded in the $\mathrm{I}_{2}$ wavelength region (red trace). On 25 and 26 August 2002, the levels of $I_{2}$ were frequently above the detection limit (blue trace), reaching peak mixing ratios in excess of 25 parts per trillion (ppt).

In order to find out whether these levels produce significant iodine atom fluxes, it is necessary to calculate their rate of dissociation under daytime marine boundary layer conditions.

\section{Determination of the photolysis rate of molecular io- dine and coastal zone iodine atom flux}

The photolysis rate of molecular iodine was directly determined in the laboratory by an optical absorption technique (Saiz-Lopez et al., 2004) in order to confirm the rates calculated from the absorption cross-section, measured or modelled actinic flux and reported quantum yield. With the light intensity at one solar constant in these experiments, the observed first-order destruction rate of $\mathrm{I}_{2}$, corresponding to its photolysis, was $0.14 \mathrm{~s}^{-1}$. In this same study, a newly measured high resolution $\mathrm{I}_{2}$ absorption crosssection from $\lambda=182$ to $750 \mathrm{~nm}$ was reported. This is in good agreement with the more coarsely resolved measurement of Tellinghuisen (1973). Using a two-stream radiative transfer model (see McFiggans et al., 2000), previously reported values of unity for the $I_{2}$ quantum yield (Rabinowitch and Wood, 1936) and the new absorption cross-section, a midday, mid-latitude, midsummer photolysis rate yielding 2 iodine atoms was calculated to be in very good agreement at $0.15 \mathrm{~s}^{-1}$.

Diiodomethane has previously been identified as the measured iodocarbon providing the greatest iodine atom flux. Using the DOAS measured $\mathrm{I}_{2}$, measurements of $\mathrm{CH}_{2} \mathrm{I}_{2}$ made at $\sim 20 \mathrm{~m}$ asl, approximately $50 \mathrm{~m}$ from the high tide 


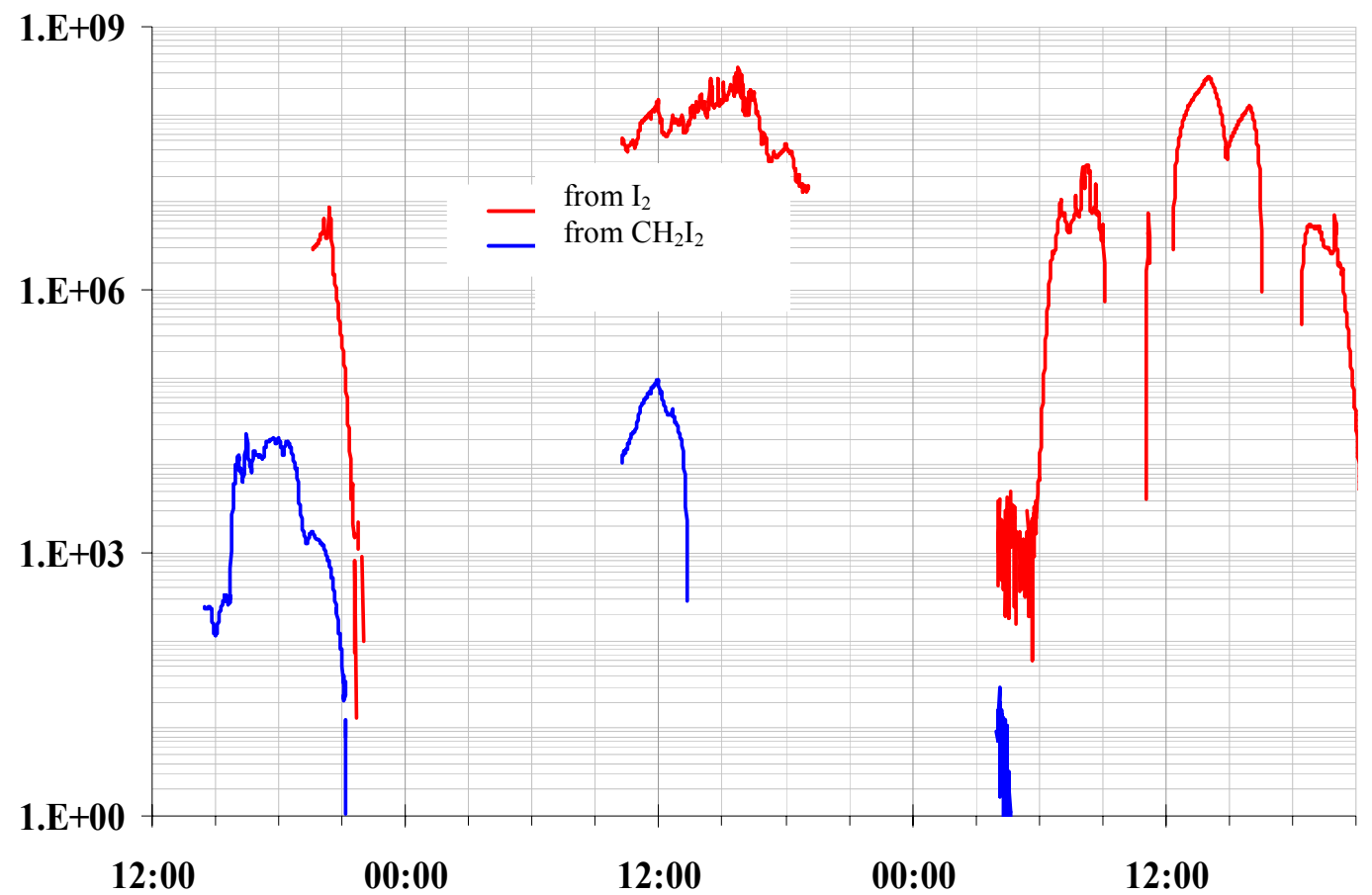

Fig. 9. Iodine atom flux from the photolysis of $\mathrm{I}_{2}$ and $\mathrm{CH}_{2} \mathrm{I}_{2}$ at Mace Head on 25 and 26 August 2002 (note that there were no measurements of $\mathrm{CH}_{2} \mathrm{I}_{2}$ after dawn on 26 August). It can be seen that there was at least three orders of magnitude greater atomic iodine flux from the photolysis of the available molecular iodine than from the photolysis of $\mathrm{CH}_{2} \mathrm{I}_{2}$; on many occasions this difference was much greater.

mark using a Perkin Elmer Turbomass GC-MS (Wevill and Carpenter, 2003) and wavelength resolved surface actinic flux levels measured by spectral radiometry (Edwards and Monks, 2003) it is possible to directly compare the iodine atom flux at Mace Head whenever there was overlap from the measurements. Figure 9 shows such a comparison (note that only where the time series were continuous were measurements available). It can be seen that there was at least three orders of magnitude greater atomic iodine flux from the photolysis of the available molecular iodine than from the photolysis of $\mathrm{CH}_{2} \mathrm{I}_{2}$; on many occasions this difference was much greater. It should be noted that this comparison assumes that the DOAS measured $\mathrm{I}_{2}$ is well mixed along the instrument's light path and that $\mathrm{CH}_{2} \mathrm{I}_{2}$ is well mixed up to the sampling inlet at $20 \mathrm{~m}$. If the $\mathrm{I}_{2}$ source is solely in the intertidal zone, a maximum of only a few hundred metres of the path, the calculated atomic iodine flux from molecular iodine could be a further factor of 20 to 50 times greater (though this may be partially offset by iodocarbons being more concentrated in the lowest few metres rather than mixed up to the sampling height). Since the GC/MS measured in selective ion mode, it is possible that other organic iodine compounds are present which may significantly contribute to the iodine atom flux. However, although both iodoform $\left(\mathrm{CHI}_{3}\right)$ and iododibromomethane $\left(\mathrm{CHIBr}_{2}\right)$ have been identified in seawater around incubated seaweeds, no species more photolabile than $\mathrm{CH}_{2} \mathrm{I}_{2}$ have been isolated in the atmosphere. It is likely therefore that any particles comprising mainly iodine oxides are derived from molecular iodine, not organic iodine.

\section{A hypothesised mechanism for coastal new particle production}

Laminaria species accumulate iodine to levels up to 30000 times more concentrated than seawater (Küpper et al., 1998). They exchange the iodine with the seawater depending on the oxidising environment of the plant. The reader is referred to Küpper et al. (1998), for a discussion of the factors affecting this transfer. Once the iodine species have diffused across the cell membrane into the apoplast, they are in free diffusive contact with the surrounding seawater. The studies of Dangeard (1928) and Kylin (1929) showed that iodovolatilisation took place in the apoplast and required oxygen. More recently it has been shown (Küpper et al., 1998) that the oxidation of iodide $\left(\mathrm{I}^{-}\right)$by hydrogen peroxide in the apoplast leads to the formation of hypoiodous acid (HOI). It is known that $\mathrm{HOI}$ and $\mathrm{I}^{-}$establish an equilibrium with molecular iodine in aqueous solution (Truesdale, 1995):

$\mathrm{HOI}+\mathrm{I}^{-}+\mathrm{H}^{+} \longleftrightarrow \mathrm{I}_{2}+\mathrm{H}_{2} \mathrm{O}$

As the water recedes, the kelp beds are uncovered such that at low tide, complete plants may be exposed, covered only with a film of water. The plants will also be exposed to the 
oxidising atmosphere. The oxidative formation of $\mathrm{HOI}$ in the apoplast will lead to a strong iodine solution in free diffusion with the thin water film. This will lead to displacement of the equilibrium towards molecular iodine. Being of limited solubility and relatively volatile, the molecular iodine will then equilibrate between aqueous solution and the gas phase. An additional contribution to the $\mathrm{I}_{2}$ release is that the oxidative stress on the seaweed during low tide atmospheric exposure may lead to direct $\mathrm{I}_{2}$ formation on oxidation of $\mathrm{I}^{-}$by $\mathrm{H}_{2} \mathrm{O}_{2}$ (Luther et al, 1993). This may lead directly to atmospheric emission. The crucial requirement is that $I_{2}$ volatilises before it can react with organic material in the seawater. Whichever mechanism is responsible for forming the $I_{2}$, it is postulated that low tide enables it to escape from the water film before it has a chance to react with organic material. This cannot happen at higher water. Either mechanism for $I_{2}$ release is consistent with this study, and resolution of this question is beyond the scope of this study. On the basis of the evidence presented here, it is suggested that the molecular iodine released into the atmosphere in this way photolyses to provide the majority of the available iodine atoms that react with atmospheric ozone leading to the formation of iodine monoxide. The self-reaction of iodine monoxide leads to the formation of higher oxides, the subsequent polymerisation of which lead to clusters, growing by further condensation to form the iodine containing particles. Burkholder et al. (2003) have explored a subset of this mechanism (the clustering of OIO only) in their study of the photolysis of $\mathrm{CF}_{3} \mathrm{I}$ and $\mathrm{CH}_{2} \mathrm{I}_{2}$ and find that published IO and OIO concentrations are incapable of explaining the observed particle bursts. A more extensive clustering mechanism based on an extension of the current work is the subject of ongoing laboratory and modelling studies.

\section{Comment on possible effect on climate change}

Considered alongside the results from the chamber study, it is unlikely that particles observed in the coastal boundary layer are formed from diiodomethane photo-oxidation, given the relative iodine atom flux from molecular iodine. More importantly, laboratory experiments indicate that intense particle formation does not appear to rely on iodinecontaining compounds condensing on sulphate TSCs under ambient conditions. Since this is the mechanism that has been proposed for TSC stabilisation, it is not certain that macroalgal iodine particles will contribute to cloud condensation nuclei or affect global radiative forcing in this way. In order to investigate whether there is such a contribution to $\mathrm{CCN}$ number, the exact formation route for the "iodine-only" particles must be established. In particular the role of inorganic iodine compounds, specifically molecular iodine, must be investigated.

This is not to say that the requirement for TSCs in the ambient atmosphere is resolved. Whilst in the Burkholder et al. (2003), Jimenez et al. (2002) and the current study no TSCs were needed to form the particles, in all cases no pre-existing aerosol were introduced into the laboratory systems. Pre-existing seasalt and probably sulphate aerosol will always be present in the coastal atmosphere and may provide a condensation sink for the precursor iodine oxides. It is well established that heterogeneous nucleation is favoured over homogeneous since the energy barrier is lowered by a pre-existing soluble or insoluble nucleus. The competition for iodine oxide vapours with the pre-existing accumulation mode aerosol may not be won by a homogeneous process such as those leading to particle formation in the current studies, but may be won by a process of stabilisation of background TSCs. Iodine-containing particles may therefore participate in climate forcing in one of two ways: iodine species may be involved in stabilisation of TSCs, or particles formed from only iodine species may directly lead to $\mathrm{CCN}$ formation. Iodine-only particle formation must then be investigated in competition with condensational growth of iodine compounds onto TSCs to establish whether it is possible for iodine chemistry to lead to an enhanced number of particles crossing the coagulation barrier and hence to assess the effect on CCN population and radiative forcing. This is the subject of an ongoing study.

\section{The main fate of algal emissions of iodine}

In the laboratory experiments, the formation of particles requires that the macroalgal samples are exposed to ozonised air or that ozone is mixed in to air that has directly passed over the specimen. Passing air over submerged samples does not lead to particle formation. However, Laminaria species occur mainly in the sublittoral zone down to $20 \mathrm{~m}$ depth of water and the vast majority of Laminarial biomass is only infrequently exposed to the atmosphere. Iodine accumulation will occur predominantly at depth and iodine release (as $\mathrm{HOI}$ in equilibrium with $\mathrm{I}_{2}$ ) will occur into the water column where it will react with dissolved organic material (DOM) to yield iodocarbon species including $\mathrm{CH}_{2} \mathrm{I}_{2}$. This sublittoral production of dissolved iodocarbons, in addition to open ocean release from microalgae, will greatly exceed direct emission of inorganic iodine into the atmosphere in the infralittoral zone at low tide. This study shows that the coastal new particle bursts result from molecular iodine released directly into the atmosphere from Laminaria macroalgae. The regional and global implications of these particles must be evaluated. However, this will be a minor fate of marine emissions of iodine. The ability of photolabile iodocarbons (the major reservoir of free iodine from algal emissions), or their breakdown products, to escape the water column and the mechanism for this release will determine the ability for reactive iodine to participate in both ozone destruction cycles and the formation of new particles in the more remote marine environment. These processes must be 
extensively studied to evaluate the atmospheric implications of algal iodine emissions.

Acknowledgements. The authors would like to thank R. EvansGowing in the School of Biological Sciences at the University of East Anglia for the TEM analyses. We would also like to thank the referees, F. Küpper and G. Malin for their valuable comments. This work was supported by UK Natural Environment Research Council grant NER/A/S/2002/00551.

Edited by: T. Hoffmann

\section{References}

Allan, B. J., Plane, J. M. C., and McFiggans, G.: Observations of OIO in the remote marine boundaryt layer, Geophys. Res. Letts., 28, 1945-1948, 2001.

Allan, J. D., Jimenez, J. L., Williams, P. I., Alfarra, M. R., Bower, K. N., Jayne, J. T., Coe, H., and Worsnop, D. R.: Quantitative sampling using an Aerodyne aerosol mass spectrometer - I. Techniques of data interpretation and error analysis, J. Geophys. Res., 108, 4090, 2003.

Brewer, L. and Tellinghuisen, J.: Quantum yield for unimolecular dissociation of $\mathrm{I}_{2}$ in visible absorption, J. Phys. Chem., 56, 39293938, 1972.

Burkholder, J. B., Curtius, J., Ravishankara, A. R., and Lovejoy, E. R.: Laboratory studies of the homogeneous nucleation of iodine oxides, Atmos. Chem. Phys. Discuss., 3, 4943-4988, 2003.

Carpenter, L. J., Sturges, W. T., Penkett, S. A., Liss, P. S., Alicke, B., Heibestreit, K., and Platt, U.: Short-lived alkyl iodides and bromides at Mace Head: links to macroalgal emissions and halogen oxide formation, J. Geophys. Res., 104, 1679-1689, 1999.

Carpenter, L. J., Malin, G., Liss, P. S., and Küpper, F. C.: Novel biogenic iodine-containing trihalomethanes and other short-lived halocarbons in the coastal East Atlantic, Glob. Geochem. Cycles, 14, 1191-1204, 2000.

Dangeard, P.: Sur le dégagement d'iode chez les algues marines, C. R. Acad. Sciences Paris, 186, 892-894, 1928.

Dangeard, P.: L'iode des algues, les ioduques, l'iodovolatilisation, Le Botaniste, 41, 187-207, 1957.

Edwards, G. D. and Monks, P.S.: Performance of a single monochromator diode array spectroradiometer for the determination of actinic flux and atmospheric photolysis frequencies, J. Geophys. Res., 108, 8546, doi:10.1029/2002JD002844, 2003.

Jayne, J. T., Leard, D. C., Zhang, X. F., Davidovits, P., Smith, K. A., Kolb, C. E., and Worsnop, D. R.: Development of an aerosol mass spectrometer for size and composition analysis of submicron particles, Aerosol Sci. Technol., 33, 49-70, 2000.

Jimenez, J. L., Bahreini, R., Cocker, D. R., Zhuang, H., Varutbangkul, V., Flagan, R. C., Seinfeld, J. H., O’Dowd, C. D., and Hoffmann, T.: New Particle Formation from Photooxidation of Diiodomethane $\left(\mathrm{CH}_{2} \mathrm{I}_{2}\right)$, J. Geophys. Res., 108, D10, 4318, doi:10.1029/2002JD002452, 2003a.

Jimenez, J. L., Jayne, J. T., Shi, Q., Kolb, C. E., Worsnop, D. R., Yourshaw, I., Seinfeld, J. H., Flagan, R. C., Zhang, X., Smith, K. A., Morris, J. W., and Davidovits, P.: Ambient aerosol sampling using the Aerodyne Aerosol Mass Spectrometer, J. Geophys. Res.-Atmos., 108, 8425, doi:10.1029/2001JD001213, 2003b.

Kolb, C.: Iodine's air of importance, Nature, 417, 597-598, 2002.
Küpper, F. C., Schweigert, N., Ar Gall, E., Legendre, J.-M., Vilter, H., and Kloareg, B.: Iodine uptake in Laminariales involves extracellular, haloperoxidase-mediated oxidation of iodine, Planta, 207, 163-171, 1998.

Kylin, H.: Über das Vorkommen von Jodiden, Bromiden und Jodidoxydasen bei Meersalgen, Hoppe-Seyler's Z. Physiol. Chem., 186, 50-84, 1929.

Mäkelä, J. M., Hoffmann, T., Holzke, C., Vakeva, M., Suni, T., Mattila, T., Alto, P. P., Tapper, U., Kauppinen, E. I., and O’Dowd, C. D.: Biogenic iodine emissions and identification of end-products in coastal ultrafine particles during nucleation bursts, J. Geophys. Res., 107, D19, 8110, 2002.

McFiggans, G., Plane, J. M. C., Allan, B. J., Carpenter, L. J., Coe, H., and O'Dowd, C.: A modeling study of iodine chemistry in the marine boundary layer, J. Geophys. Res., 105, 14 371-14385, 2000.

O’Dowd, C., McFiggans, G., Creasey, D. J., Pirjola, L., Hoell, C., Smith, M. H., Allan, B. J., Plane, J. M. C., Heard, D. E., Lee, J. D., Pilling, M. J., and Kulmala, M.: On the photochemical production of new particles in the coastal boundary layer, Geophys. Res. Lett., 26, 1707-1710, 1999.

O’Dowd, C. D., Hämeri, K., Mäkelä, J. M., et al.: A dedicated study of new particle formation and fate in the coastal environment (PARFORCE): Overview of objectives and achievements, J. Geophys. Res., 107, D19, 8108, doi:10.1029/2001JD000555, 2002.

O’Dowd, C., Jimenez, J. L., Bahreini, R., Flagan, R. C., Seinfeld, J. H., Hämeri, K., Pirjola, L., Kulmala, M., Jennings, S. G., and Hoffmann, T.: Marine aerosol formation from biogenic iodine emissions, Nature, 417, 632-636, 2002.

Pirjola, L., O'Dowd, C. D., Brooks, I. M., and Kulmala, M.: Can new particle formation occur in the clean marine boundary layer?, J. Geophys. Res., 105, 26 531-26 546, 2000.

Rabinowitch, E. and Wood, R. C.: Dissociation of excited iodine molecules, J. Chem. Phys., 4, 358-362, 1936.

Rao, M. V., Koch, J. R., and Davis, K. R.: Ozone: a tool for probing programmed cell death in plants, Plant Molecular Biology, 44, 345-358, 2000.

Rader, D. J. and McMurry, P. H.: Application of the tandem differential mobility analyser for studies of droplet growth or evaporation, J. Aerosol Science, 17, 771-787, 1986.

Rodgers, C. D.: Inverse methods for atmospheric sounding, Theory and practice, Series on atmospheric, oceanic and planetary physics, Vol. 2, World Scientific, 2000.

Saiz-Lopez, A., Saunders, R. W., Joseph, D. M., Ashworth, S. H., and Plane, J. M. C.: Absolute absorption cross-section and photolysis rate of $\mathrm{I}_{2}$, Atmos. Chem. Phys. Disc., 2379-2403, 2004.

Saiz-Lopez, A. and Plane, J. M. C.: Novel iodine chemistry in the marine boundary layer, Geophys. Res. Letts., 31, L04112, doi:10.1029/2003GL019215, 2004.

Sunder, S., Wren, J. C., and Vikis, A. C.: Raman spectra of $\mathrm{I}_{4} \mathrm{O}_{9}$ formed by the reaction of iodine with ozone, Journal of Raman Spectroscopy, 16, 424-426, 1985.

Sunder, S. and Vikis, A. C.: Raman spectra of iodine oxyacids produced by the gas-phase reaction of iodine with ozone in the presence of water vapour, Canadian Journal of Spectroscopy, 32, 4548, 1987.

Truesdale, V. W., Luther III, G. W., and Canosa-Mas, C.: Molecular iodine reduction in seawater: an improved rate equation consid- 
ering organic compounds, Mar. Chem., 48, 143-150, 1995.

Vakeva, M., Hameri, K., and Aalto, P. P.: Hygroscopic properties of nucleation mode and aitken mode particles during nucleation bursts and in background air, J. Geophys. Res., 107, (D19), 8104, doi:10.1029/2000JD000176, 2002.

Vikis, A. C. and MacFarlane, B.: Reaction of iodine with ozone in the gas phase, J. Phys. Chem., 89, 812-815, 1985.

Wevill, D. and Carpenter, L. J.: An automated GC-MS method for the atmospheric measurement of reactive volatile halogenated organic compounds, The Analyst, doi:10.1039/B403550J, 2004.
Winklmayr, W., Reischl, G. P., Lindner, A. O., and Berner, A.: A New Electromobility Spectrometer for the Measurement of Aerosol Size Distributions in the Size Range from 1 to $1000 \mathrm{~nm}$, J. Aerosol. Sci., 22, 289-296, 1991.

Zhang, X. F., Smith, K. A., Worsnop, D. R., Jimenez, J., Jayne, J. T., and Kolb, C. E.: A numerical characterization of particle beam collimation by an aerodynamic lens-nozzle system: Part I., An individual lens or nozzle, Aerosol Sci. Tech., 36, 617-631, 2002. 